\title{
Use of Clearance Indexes to Assess Waste Disposal Issues for the HYLIFE-II Inertial Fusion Energy Power Plant Design
}

S. Reyes, J. Sanz, J.F. Latkowski

This article was submitted to

$6^{\text {th }}$ International Symposium on Fusion Nuclear Technology, San Diego, California, April 7-12, 2002

U.S. Department of Energy

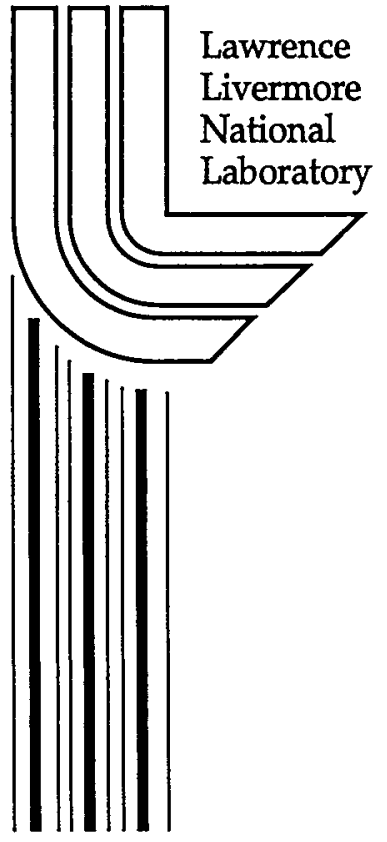

January 17, 2002 


\section{DISCLAIMER}

This document was prepared as an account of work sponsored by an agency of the United States Government. Neither the United States Government nor the University of California nor any of their employees, makes any warranty, express or implied, or assumes any legal liability or responsibility for the accuracy, completeness, or usefulness of any information, apparatus, product, or process disclosed, or represents that its use would not infringe privately owned rights. Reference herein to any specific commercial product, process, or service by trade name, trademark, manufacturer, or otherwise, does not necessarily constitute or imply its endorsement, recommendation, or favoring by the United States Government or the University of California. The views and opinions of authors expressed herein do not necessarily state or reflect those of the United States Government or the University of California, and shall not be used for advertising or product endorsement purposes.

This is a preprint of a paper intended for publication in a journal or proceedings. Since changes may be made before publication, this preprint is made available with the understanding that it will not be cited or reproduced without the permission of the author.

This report has been reproduced directly from the best available copy.

Available electronically at http://www.doe.gov/bridge

Available for a processing fee to U.S. Department of Energy and its contractors in paper from

U.S. Department of Energy

Office of Scientific and Technical Information

P.O. Box 62

Oak Ridge, TN 37831-0062

Telephone: (865) 576-8401

Facsimile: (865) 576-5728

E-mail: reports@adonis.osti.gov

Available for the sale to the public from

U.S. Department of Commerce

National Technical Information Service

5285 Port Royal Road

Springfield, VA 22161

Telephone: (800) 553-6847

Facsimile: (703) 605-6900

E-mail: orders@ntis.fedworld.gov

Online ordering: http://www.ntis.gov/ordering.htm

OR

Lawrence Livermore National Laboratory

Technical Information Department's Digital Library

http://www.llnl.gov/tid/Library.html 


\title{
Use of Clearance Indexes to Assess Waste Disposal Issues for the HYLIFE-II Inertial Fusion Energy Power Plant Design
}

\author{
S. Reyes ${ }^{a}$, J. Sanz ${ }^{\text {, J. F. Latkowski }}{ }^{\mathrm{a}}$ \\ 'Lawrence Livermore National Laboratory, P. O. Box 808, L-641, Livermore, CA 94550 \\ ${ }^{b}$ UNED/ ETS Ingenieros Industriales, Dpto. Ingenieria Energetica, C/ Ciudad Universitaria s/n, 28040 Madrid, \\ Spain. Also: Instituto Fusion Nuclear, Madrid, Spain
}

\begin{abstract}
Traditionally, waste management studies for fusion energy have used the Waste Disposal Rating (WDR) to evaluate if radioactive material from irradiated structures could qualify for shallow land burial. However, given the space limitations and the negative public perception of large volumes of waste, there is a growing international motivation to develop a fusion waste management system that maximizes the amount of material that can be cleared or recycled.

In this work, we present an updated assessment of the waste management options for the HYLIFE-II inertial fusion energy (IFE) power plant, using the concept of Clearance Index (CN) for radioactive waste disposal. With that purpose, we have performed a detailed neutronics analysis of the HYLIFE-II design, using the TART and ACAB computer codes for neutron transport and activation, respectively. Whereas the traditional version of $A C A B$ only provided the user with the WDR as an index for waste considerations, here we have modified the code to
\end{abstract}


calculate Clearance Indexes using the current International Atomic Energy Agency (IAEA) clearance limits for radiological waste disposal. The results from the analysis are used to perform an assessment of the waste management options for the HYLIFE-II IFE design.

\section{Introduction}

The safe handing of radioactive waste is recognized as vital to ensure protection of human health and the environment. It is also required for the public to accept fusion energy. Previous waste management studies for inertial fusion energy have traditionally used the Waste Disposal Rating to evaluate if neutron activated material from an IFE power plant would qualify for shallow land burial (WDR < 1) [1]. However, given the space limitations and the negative public perception of large volumes of waste (even in the case of low activation materials), the international community has lately focused its efforts on developing a fusion waste management system that maximizes the amount of fusion materials that can be automatically released from regulatory control or "cleared". The IAEA has proposed levels of radionuclides in solid materials below which traditional regulation may be relinquished on the grounds that the associated radiation hazards are trivial [2]. The radiological basis for this guidance is the international consensus on principles for the exemption of radiation sources from regulatory control reached in 1988 [3]. These levels are intended as international reference values and may be seen as those below which radioactive waste can be cleared, i.e. released from regulatory control without further consideration [2]. 
In this work we have applied the concept of clearance levels to the HYLIFE-II IFE power plant design [4]. Since the times of the original design, safety and environmental characteristics of HYLIFE-II have been analyzed in detail $[5,6]$. This design uses a heavy ion driver for indirect illumination of the targets and is based on the concept of thick liquid protection to increase the lifetime of components, thus reducing the volume of radioactive waste. However, this volume would still be significant in the case of the confinement building $\left(\approx 5 \cdot 10^{3} \mathrm{~m}^{3}\right.$ of concrete).

In the present work, we have updated the neutronics analysis for HYLIFE-II, obtaining not only the WDRs but also the Clearance Indexes for the different components to determine if any of the power plant structures could be cleared for unconditional use after the full power plant life. For that purpose, we have implemented the calculation of CIs in the activation code using current IAEA limits for radiological waste disposal. The results from the analysis are used to perform an assessment of the waste management options for the HYLIFE-II IFE design.

\section{Computational Procedures}

A 3-D model of HYLIFE-II was created for the neutronics analysis. The TART Monte Carlo code for neutron and photon transport [7] has been used to obtain the neutron spectrum in 175 energy groups for the different zones of interest in the power plant. The model includes the 60cm-thick flibe $\left(\mathrm{Li}_{2} \mathrm{BeF}_{4}\right)$ inner pocket, the stainless steel type-304 (SS304) chamber/blanket structures with the additional flibe circuits between the first three shells, and a concrete shielding for final focus magnet protection. We have also included a 1-m-thick confinement concrete building at $20 \mathrm{~m}$ from the target. 
With this model we have obtained the energy-dependent neutron fluxes in the flibe, SS304 and concrete structures. The neutron fluxes have then been used to calculate the activation of materials with the $\mathrm{ACAB}$ code [8], a computer program designed to perform activation and transmutation calculations for fusion applications. We have calculated the activation of components following 30 years of full-time operation, obtaining results during the period of irradiation and up to 100 years of cooling after the shutdown of the power plant.

The traditional version of ACAB gives the WDR index for waste considerations. The WDRs are used to determine if a particular component can be disposed via shallow land burial. They are calculated by $\mathrm{ACAB}$ using the specific activity limits given by Fetter et al. [9]. The WDRs are calculated for each radionuclide, and summation over all radionuclides provides a single value that allows components to be compared to one another. A WDR less than unity indicates that a component would qualify for shallow land burial (assuming that regulations for fusion-relevant radionuclides are implemented on the same basis as those that have been implemented for fission waste). However, given the space limitations and the negative public perception of large volumes of waste, shallow land burial is not necessarily the best method of waste disposal.

Thus, here we have implemented the calculation of Clearance Indexes in ACAB using the current IAEA clearance limits. The way these indexes are calculated and their meaning are explained next.

\section{Calculation of Clearance Indexes}


The Clearance Index $(\mathrm{CI})$ for a material containing a single radionuclide $n$ is calculated by Equation 1, where $A_{n}$ is the activity due to the nuclide and $L_{n}$ is the IAEA clearance level for the nuclide. If $\mathrm{CI} \leq 1$ then it is possible to clear the material.

$$
C I=\frac{A_{n}}{L_{n}}
$$

Most materials contain a mixture of radionuclides, and in this case the Clearance Index is calculated by Equation 2. Again, clearance is possible if $\mathrm{CI} \leq 1$.

$$
C I=\sum_{i} \frac{A_{i}}{L_{i}}
$$

In Equations 1 and 2, activities and clearance levels have units of $\mathrm{Bq} \cdot \mathrm{kg}^{-1}$. Reference [10] gives clearance values for a number of nuclides and a general formula that can be used to calculate the level for any other nuclide. The formula is given in Equation 3,

$$
L_{i}=\min \left\{\frac{1000}{E_{\gamma, i}+0.1 \times E_{\beta, i}}, \frac{D}{e_{i}^{\text {inh }}}, \frac{D}{e_{i}^{\text {ing }} \times 10^{2}}\right\}
$$

where: $D=20 \mathrm{mSv} \cdot \mathrm{y}^{-1}$, i.e. the dose limit for radiation workers [11], and for the $i^{\text {th }}$ nuclide, the other quantities are: $E_{\gamma, \mathrm{i}}$ - effective photon emission energy $(\mathrm{MeV}) ; E_{\beta, \mathrm{i}}$ - effective beta decay emission energy $(\mathrm{MeV}) ; e_{i}{ }^{i n h}-$ committed effective dose equivalent from inhalation $\left(\mathrm{Sv} \cdot \mathrm{Bq}^{-1}\right)$ and $e_{i}{ }^{\text {ing }}-$ committed effective dose equivalent from ingestion $\left(\mathrm{Sv} \cdot \mathrm{Bq}^{-1}\right)$. Note that these quantities are available in the EAF_DEC-99 and EAF_HAZ-99 libraries [12, 13]. Equation 3 was used to calculate $L_{i}$ values for all nuclides not given explicitly in reference [10].

\section{Results}


Using the results from neutron transport and activation calculations for the HYLIFE-II design, we have obtained the waste disposal indexes for the different components. First, the WDRs were calculated for the coolant (flibe), blanket structures, inner shielding and confinement building. Table I shows not only the WDR but also the life-cycle waste volume (LCWV) for each component. It can be observed that all of the structures would qualify for shallow land burial (WDR $<1$ ), and the waste volume is dominated by the $5300 \mathrm{~m}^{3}$ of concrete from the confinement building.

Figure 1 shows the Clearance Index for the different reactor structures as a function of the time after shutdown. It can be observed that in the cases of the stainless steel structures, the flibe coolant and the inner shielding, the best waste management option would still be shallow land burial, given that clearance of these materials is not possible ( $\mathrm{CI}>1)$. The confinement building, however, reaches the clearance level after about one year of cooling. Since the volume of the concrete building dominates the total life-cycle waste volume of the power plant, this is a significant S\&E advantage for HYLIFE-II. Also, the cooling time for the building to reach the clearance level $(\sim 1$ year) is quite short compared to the anticipated decommissioning time for the plant.

\section{Conclusions}

Previous IFE studies have traditionally used the WDRs as waste disposal index in order to determine if a particular component qualifies for shallow land burial disposal. However this may not be the best waste management option if one has to dispose of relatively large volumes. 
In this work, we have introduced the concept of Clearance Indexes in order to determine if components of the HYLIFE-II inertial fusion energy power plant could be cleared from regulatory control.

We modified the activation code $\mathrm{ACAB}$ to include the calculation of Clearance Indexes, and we calculated both the WDRs and CIs for each component of the power plant. Although all of the structures would meet the requirement for shallow land burial (WDR $<1$ ), the total volume is significant and undesirable. On the other hand, the results on CIs show that in the case of the confinement building, which dominates the total volume of the waste stream, clearance would be possible after about one year of cooling following the shutdown of the plant.

This result represents a very attractive option for waste management considerations of the HYLIFE-II power plant, as it means that the material could be released from regulatory control for unconditional re-use after a relatively short period of cooling. Further work on S\&E issues for IFE should focus on maximizing the amount of material that qualifies for clearance, as the preferred option for waste management.

\section{Acknowlegements}

Work performed under the auspices of the US Department of Energy by University of California Lawrence Livermore National Laboratory under Contract W-7405-Eng-48.

\section{References}


[1] J. F. Latkowski, J. Sanz, J. L. Vujic, "The Impact of Pulsed Irradiaton upon Neutron Activation Calculations for Inertial and Magnetic Fusion Energy Power Plants," Fusion Technology, 30, 1470-1474, 1996.

[2] "Clearance levels for radionuclides in solid materials. Application of exemption principles" IAEA-TECDOC-855, IAEA, 1996.

[3] "Principles of the Exemption of Radiation Sources and Practices from Regulatory Control," IAEA Safety Series No. 89, IAEA, Vienna, Austria, 1988.

[4] R. W. Moir, R. L. Bieri, X. M. Chen, T. J. Dolan, M. A. Hoffman, P. A. House, R. L. Leber, J. D. Lee, Y. T. Lee, J. C. Liu, G. R. Longhurst, W. R. Meier, P. F. Peterson, R. W. Petzoldt, V. E. Schrock, M. T. Tobin, W. H. Williams, "HYLIFE-II: A Molten Salt Inertial Fusion Energy Power Plant Design - Final Report,” Fusion Technology, 25, 5-25, 1994.

[5] S. Reyes, J. F. Latkowski, J. Gomez Del Rio, J. Sanz, “Accident Consequences Analysis of the HYLIFE-II Inertial Fusion Energy Power Plant Design," Nuclear Instruments and Methods in Physics Research A, 464, 416-421, 2001.

[6] S. Reyes, J. F. Latkowski, J. Gomez Del Rio, J. Sanz, "Progress in Accident Analysis of the HYLIFE-II Inertial Fusion Energy Power Plant Design", Fusion Technology, 39, (2,2) 946-950 (Mar. 2001).

[7] D. E. Cullen, "TART98: A Coupled Neutron Photon, 3-D, Combinatorial Geometry, Time Dependent, Monte Carlo Transport Code,” LLNL, UCRL-ID-126455, Rev. 2, 1998.

[8] J. Sanz, "ACAB98: Activation Code for Fusion Applications. User's Manual V4.0", Universidad Nacional de Educacion a Distancia (UNED), LLNL, UCRL-CR-133040, 1999.

[9] S. Fetter, E.T. Cheng and E.M. Mann, "Long-term radioactive waste from fusion reactors: Part II," Fusion Engineering and Desigm, 13, 239, 1990. 
[10] "Clearance levels for radionuclides in solid materials: application of exemption principles," 1994 Draft Safety Guide, IAEA Safety Series No. 111.G-1-5, IAEA, Vienna, 1994.

[11] "1990 Recommendations of the International Commission on Radiological Protection" ICRP Publication 60, Annals of the ICRP 21, No 1 - 3, 1991.

[12] R. A. Forrest, J. Ch. Sublet, “The European Activation File: EAF-99 Decay Data Library," UKAEA FUS 409, 1998.

[13] R. A. Forrest, J. Ch. Sublet, "The European Activation File: EAF-99 Biological, Clearance and Transport Libraries," UKAEA FUS 410, 1998. 
Equation 1

$$
C I=\frac{A_{n}}{L_{n}}
$$


Equation 2

$$
C I=\sum_{i} \frac{A_{i}}{L_{i}}
$$


Equation 3

$$
L_{i}=\min \left\{\frac{1000}{E_{\gamma, i}+0.1 \times E_{\beta, i}}, \frac{D}{e_{i}^{i n h}}, \frac{D}{e_{i}^{i n g} \times 10^{2}}\right\}
$$


Table I. WDRs and life-cycle waste volumes (LCWVs) for the different components of the HYLIFE-II design.

\begin{tabular}{|l|c|c|}
\hline \multicolumn{1}{|c|}{ Component } & WDR & LCWV ( \\
\hline S $)$ \\
\hline SS304 blanket structures & $8.7 \mathrm{E}-01$ & $3.1 \mathrm{E}+01$ \\
\hline Flibe coolant & $2.3 \mathrm{E}-03$ & $1.2 \mathrm{E}+03$ \\
\hline Inner shielding & $3.0 \mathrm{E}-05$ & $9.1 \mathrm{E}+02$ \\
\hline Confinement building & $2.7 \mathrm{E}-05$ & $5.3 \mathrm{E}+03$ \\
\hline
\end{tabular}


Figure 1. Clearance indexes for the different components of the plant as a function of the cooling time

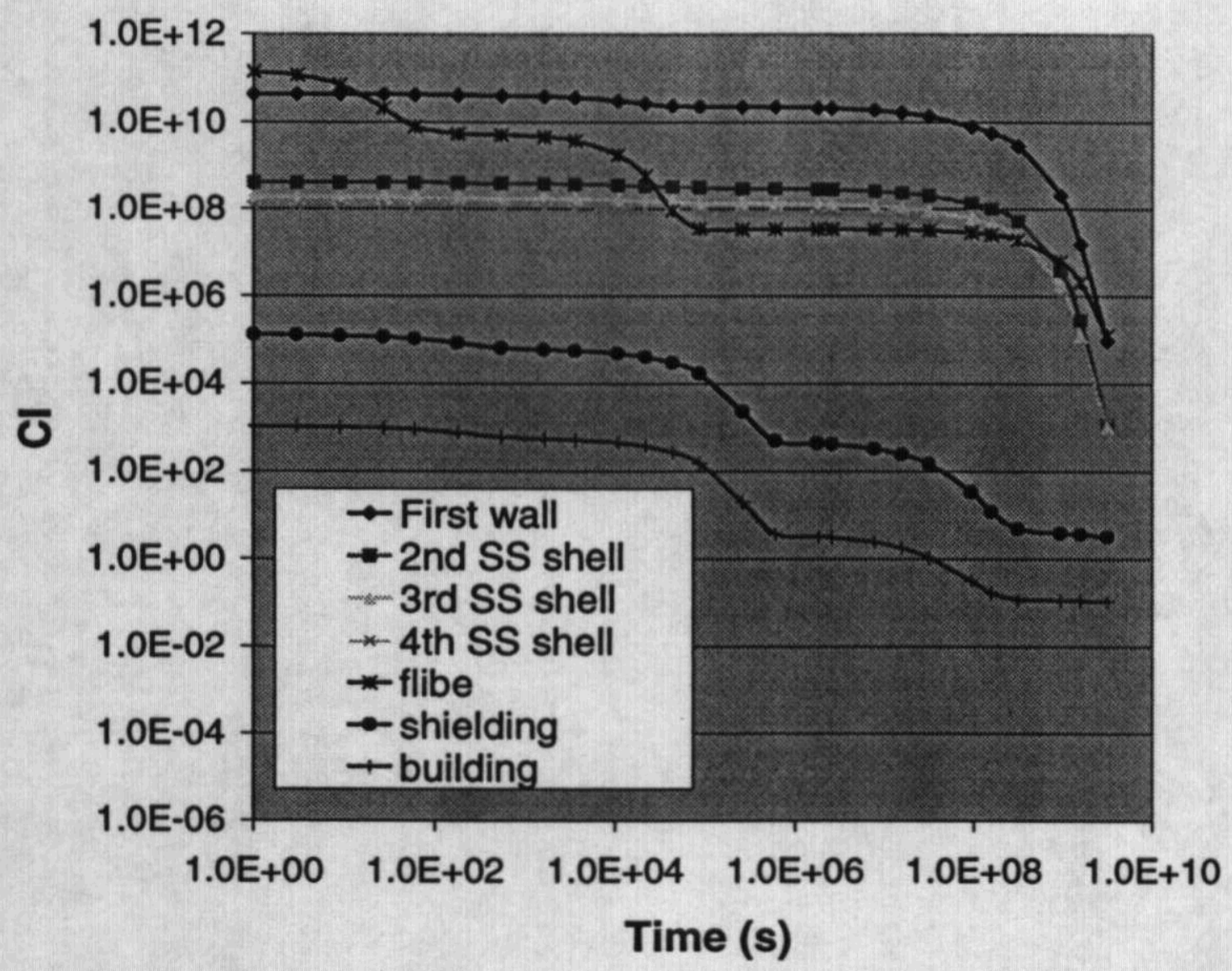

